\title{
Tecnología y educación: en busca de una pedagogía liberadora frente a la neocolonización digital ${ }^{1}$
}

\section{Tecnologia e educação: em busca de uma pedagogia libertadora frente à neocolonização digital}

\author{
Technology and education: looking for a pedagogy \\ of freedom in the face of digital neocolonization
}

\author{
Cláudia Dias Prioste ${ }^{2}$
}

DOI: http://dx.doi.org/10.20435/serie-estudos.v24i51.1300

\begin{abstract}
Resumen: El presente ensayo tiene el objetivo de discutir las nuevas formas de opresión y de colonización que se están desarrollando en la era digital, así como examinar la relevancia y la actualidad de las ideas del educador Paulo Freire sobre una pedagogía liberadora. Considerándose la potencialidad educativa de las tecnologías de la información y comunicación (TIC), que guarda la promesa de democratización del acceso a los conocimientos, un análisis crítico sobre los presupuestos pedagógicos contemporáneos se hace cada vez más relevante. El punto de partida de las reflexiones aquí presentadas se constituye de evidencias empíricas de investigaciones que desarrollo hace más de diez años, sobre el uso de las TIC por adolescentes y niños brasileños, observando sus posibles efectos en el proceso educativo. Es importante resaltar que la perspectiva crítica no debe estar reducida a una mirada fatalista del uso de las tecnologías en la educación, al contrario, se espera que las proposiciones sobre la neocolonización digital, aquí desarrolladas, puedan estimular nuevos posicionamientos pedagógicos, especialmente con relación a la escolarización de las capas populares.
\end{abstract}

Palabras clave: tecnología y educación; psicoanálisis y cibercultura; teoría crítica y tecnología.

Resumo: O presente ensaio tem o objetivo de discutir algumas novas formas de opressão e colonização que têm sido desenvolvidas na era digital, bem como examinar a relevância e a atualidade das ideais do educador Paulo Freire sobre uma pedagogia libertadora. Considerando a potencialidade educativa das tecnologias da informação e comunicação (TIC), que guarda a promessa de democratização de acesso aos conhecimentos, uma análise crítica dos pressupostos pedagógicos contemporâneos se torna cada vez mais relevante. O ponto de partida das reflexões aqui apresentadas foram as evidências empíricas de pesquisas que tenho desenvolvido, há mais

\footnotetext{
${ }^{1}$ Trabajo presentado en 4th International Scholas Chairs Congress University and School, en 2018, Castel Gandolfo, Italy.

2 Faculdade de Ciências e Letras, Universidade Estadual Paulista Júlio de Mesquita Filho (UNESP), Araraquara, São Paulo, Brasil.
} 
de dez anos, sobre o uso das TIC por adolescentes e crianças brasileiras, e seus possíveis efeitos educacionais. É importante enfatizar que uma perspectiva crítica não deve ser reduzida a uma visão fatalista sobre o uso das tecnologias na educação. Ao contrário, espera-se que as proposições sobre a neocolonização digital aqui desenvolvidas possam estimular novos posicionamentos pedagógicos, especialmente no que se refere à escolarização das camadas populares.

Palavras-chave: tecnologia e educação; psicanálise e cibercultura; teoria crítica e tecnologia.

Abstract: This essay aims to discuss some new forms of oppression and colonization that has being developed in the digital age, as well, to examine the current relevance of educator Paulo Freire's ideas concern to pedagogy of freedom. Considering the potential educational purpose of information and communication technologies (ICT) and that Its use keeps a promise of democratization of access to knowledge, a critical analysis of some contemporary pedagogical assumptions becomes increasingly relevant. The starting point of the reflections presented here are the empirical evidences of research that I have developed, over ten years ago, about the use of ICT by Brazilian adolescents and children, with their possible educational effects. It is important to emphasize that the critical perspective should not be reduced to a fatalistic view about the use of technology in education. On the contrary, It is expected that the propositions concern of digital neocolonization can stimulate new pedagogical positioning, especially on schooling of popular classes.

Keywords: technology and education; psychoanalysis and cyberculture; critical theory and technology.

\section{INTRODUCCIÓN}

La célebre frase de Eduardo Galeano "la división internacional del trabajo consiste en que unos países se especializan en ganar y otros en perder" (GALEANO, 2010 , p.) nos inspira a reflexionar sobre los mecanismos opresivos que avanzan solapadamente con el progreso tecnológico y con las ilusiones de la sociedad del conocimiento. De esta manera, mientras algunos países se benefician de las tecnologías de la información y comunicación (TIC), proyectándose así en el mercado internacional, otros países, en general, siguen con un papel pasivo y sumiso. ¿Cómo revertir este proceso, anunciado por Galeano en los años de 1970? ¿Cómo formar ciudadanos críticos, con dominio de las tecnologías y capaces de hacer frente a las desigualdades de la globalización?

Esos cuestionamientos dirigen las reflexiones presentadas. Hay que señalar, sin embargo, el perfil exploratorio de este ensayo que no se limita a una dimensión teórica específica, pero arriesga articular diferentes dominios del pensamiento. En la primera parte del trabajo presento las principales ideas de Paulo Freire sobre educación liberadora; en la segunda, desarrollo proposiciones sobre la dominación 
neocolonizadora que ocurre por medio de las imágenes técnicas; después discuto algunas teorías pedagógicas que contribuyen para reforzar las desigualdades en Brasil y expongo evidencias empíricas sobre el uso de las tecnologías por jóvenes y niños brasileños con el intuito de ejemplificar los argumentos más relevantes. Por último, propongo reflexiones en el ámbito educativo sobre cómo hacer frente a la neocolonización digital.

\section{DE LA EXPLORACIÓN Y OPRESIÓN A UNA EDUCACIÓN LIBERADORA}

Cuando Galeano publicó el clásico Las Venas Abiertas de América Latina, en los años de 1970, la condición de opresión y de servidumbre de los latinoamericanos se hizo más ampliamente discutida y explicitada. En esta obra se discutió tanto el proceso de colonización española y portuguesa, como la neocolonización británica y estadounidense. Esas potencias emergentes de la revolución industrial han encontrado en América Latina, con sus debilidades históricamente engendradas, un terreno fértil para que la mano invisible del libre mercado impusiera dominaciones económicas y políticas. Según Galeano: "nuestra riqueza ha generado siempre nuestra pobreza para alimentar la prosperidad de otros: los imperios y sus caporales nativos. En la alquimia colonial y neocolonial, el oro se transfigura en chatarra" (GALEANO, 2010, p. 16).

En la misma época, el educador Paulo Freire estaba empeñado en un análisis del proceso histórico de dominación colonialista en Brasil y de cómo la educación podría cambiar nuestra visión del mundo, en dirección a la libertad y a la democracia. En el libro Educación como práctica de la libertad, escrito durante el periodo de exilio en Chile, Freire (1997) describió la sociedad brasileña como "intensamente cambiante y dramáticamente contradictoria", cuyos desafíos implicaban algunas opciones: "opción por una sociedad parcialmente independiente u opción por una sociedad que se 'descolonizase' cada vez más" (FREIRE, 1997, p. 25).

Conviene señalar que Brasil pasaba por una dictadura que había empezado en 1964, sin embargo, Freire entendía este período como una fase de transición de una sociedad encerrada, alienada de su proceso histórico y de decisión, con foco en modelos exteriores coloniales, para una sociedad abierta y democrática. Una sociedad consciente de su proceso histórico, capaz de crear alternativas de lucha e inclusión social. 
Las explicaciones de Freire para el retroceso brasileño estaban centradas en el pensamiento mítico, en la sumisión irreflexiva a los ideales extranjeros, a la falta de experiencia democrática y a una educación que estimulaba la acomodación y la pasividad:

Una de las grandes - si no la mayor - tragedias del hombre moderno es que hoy, dominado por la fuerza de los mitos y dirigido por la publicidad organizada, ideológica o no, renuncia cada vez más sin saberlo, a su capacidad de decidir. Está siendo expulsado de la órbita de las decisiones. El hombre simple no capta las tareas propias de su época, le son presentadas por una élite que las interpreta y se las entrega en forma de receta, de prescripción a ser seguida. (FREIRE, 1997, p. 33).

Freire explica que el hombre que no es sujeto de su Historia se mantiene acomodado, domesticado, pasivo, sumiso y sin esperanza. Según Freire, el brasileño quedaba prisionero de una perspectiva gregaria y conformista, cuya integración dependía de la humanización del sujeto y de la captación de los nuevos temas, a saber: democracia, participación popular, libertad, propiedad, autoridad y educación. Además, creía en la importancia del desarrollo de las funciones intelectuales, superando las funciones instintivas y emocionales.

Esos nuevos temas deberían ser trabajados en todas las dimensiones de la educación, de manera dialógica. Según Freire (1997), la ausencia del diálogo ha sido una marca de la experiencia del brasileño, que delante de la potencia y de los señores de las tierras, respondían con mutismo o con una actitud de condescendencia, que a menudo se convertía en violencia.

La identificación con el opresor también sería una marca de nuestra cultura, como reveló Freire en Pedagogía del oprimido. Freire (2005) consideraba que los opresores, guiados por un sádico placer de dominación, convertían el hombre en cosa, en un objeto de explotación, disfrazando esa violencia con una falsa calidez. Esa deshumanización se sostenía por un fatalismo, por la creencia de que la condición del oprimido sería consecuencia de la voluntad de Dios, de un destino irremediable. Además, resaltaba el anhelo de los oprimidos en convertirse en opresores debido a la falta de conciencia de todo el proceso de dominación social en que habían sido sometidos.

Freire (2005) denunció la "pedagogía bancaria", que priorizaba a la transmisión de conocimientos sin promover crítica y transformaciones sociales 
importantes. Creía firmemente que la educación y, en particular, la alfabetización pueden ser liberadoras, es decir, podrían promover una nueva conciencia en los oprimidos. Para eso, propuso una metodología dialógica centrada en el diálogo y en el análisis de situaciones concretas de la vida.

En suma, una educación liberadora para el hombre sería:

[...] una educación que le facilitase la reflexión sobre su proprio poder de reflexionar y que tuviese su instrumentación en el desarrollo de ese poder, en la explicación de sus potencialidades, de la cual nacería su capacidad de opción. Educación que tomase en consideración los varios grados del poder de captación de que está posibilitado el hombre brasileño, factor de importancia fundamental para su humanización. (FREIRE, 1997, p. 52).

La educación liberadora estaba tácitamente vinculada a la alfabetización, al desarrollo de las funciones intelectuales, junto a la capacidad de identificar las estructuras de poder. Para ello sería fundamental la apropiación de la Historia y una consciencia de las raíces de las desigualdades.

\section{EL PODER DE LAS IMÁGENES EN EL PROCESO DE COLONIZACIÓN Y NEOCOLONIZACIÓN}

La pasividad del pueblo oprimido, reportada en Freire (2005), está estrechamente conectada al proceso histórico de violencia y manipulación psicológica promovidas por los colonizadores y neocolonizadores. El historiador francés Serge Gruzinsk (1990) en Les guerres des images: de Christophe Colomb à 'Blade Runner' (1492-2019), demostró el papel estratégico de las imágenes en el proceso de colonización de América Latina. Las principales armas de los portugueses y españoles fueron la pólvora, las bacterias y el adoctrinamiento con el uso de imágenes. Los jesuitas, a través del choque de imágenes, acompañado de narraciones míticas y heroicas del cristianismo, han creado un imaginario favorable a la dominación. Aunque este proceso no ha ocurrido sin resistencia y ambivalencia, es importante observar el conjunto de fuerzas de las imágenes que operan junto a la fuerza bruta de la pólvora. Gruzinski (1990) se apoya en la hipótesis de que hay un lazo entre la forma de dominación por medio de las imágenes barrocas y la dominación por medio de las imágenes televisuales, cuyas características en común son la saturación, la pluralidad, la pletórica y la presencia repetitiva. 
La palabra "colonia" tiene una estrecha conexión con vivir, trabajar y ocupar la tierra: "colo es la matriz de colonia, como un espacio que está siendo ocupado, tierra o pueblo que se puede trabajar y someter" (BOSI, 1992, p. 11, traducción propia). El sentido da palabra colonia no solo puede ser aplicado a las formas de dominaciones reducidas a la explotación de los recursos naturales y del trabajo del pueblo, sino también a la explotación de la diversión y de los espacios digitales.

La atención del individuo, su tiempo libre y sus espacios de socialización pasan a ser cada vez más disputados con la expansión del acceso a la internet y con la proliferación de gadgets. Sostenemos la hipótesis de que las nuevas formas de dominación psicológica, mercadológica y política impetradas por medio de las TIC, pueden ser sintetizadas en la concepción de neocolonización digital. El enfoque de la neocolonización digital es la disputa por la ocupación del ciberespacio, de los ambientes digitales, televisivos y del tiempo de cerebro disponible de cada individuo. La neocolonización digital puede ser entendida como un proceso de dominación impetrado por los países que poseen tecnologías más avanzadas y privilegios en el control de la información y de las imágenes que circulan en la televisión y en la internet, ejerciendo influencias económicas y políticas en los países en condiciones de mayor vulnerabilidad. Esa neocolonización ocurre a través de un encantamiento hecho por las imágenes, en las cuales magia y religión se mezclan, sin pudor, a los placeres voyeurísticos, exhibicionistas y sádicos. Placeres que son disfrutados en las telenovelas, diseños animados, seriados norteamericanos, noticiarios sensacionalistas, juegos digitales, redes sociales o en los sitios de pornografía virtual, como explicitamos adelante con algunos extractos de investigaciones.

El filósofo Jean-Jacques Delfour (2011) en Télé, bagnole et autres prothèses du sujet moderne: essai sur la jouissance technologique, argumenta que la visión a distancia fue fundamental en el proceso de dominación de los pueblos. Los instrumentos de ver desde lejos, el telescopio, y de matar a distancia fueron determinantes en las guerras. Como ejemplo, Delfour cita la batalle de Wagram de 1809, inmortalizada en la pintura de Horace Vernet (1836) que retrata Napoleón con un telescopio, sobre un caballo, delante de la artillaría lista para atacar. Es un cuadro emblemático del poder telescópico; "la tecnología de muerte a distancia favorece la ilusión de inocencia no solo de los tiradores, pero de aquellos que comandan (DELFOUR, 2011, p. 18, traducción propia). Las tecnologías de ver a 
distancia, o sea, las tele - visiones, inauguran un nuevo momento de disolución de la responsabilidad y de la culpabilidad, y fortalecen el posicionamiento del poder. La deshumanización también sucede con aquellos que se regocijan con las imágenes de poder y muerte.

La polarización del campo sociopolítico depende de una bipolarización psicotecnológica del campo perceptivo donde la asimetría de la distancia es la garantía que uno de los polos sea aquel del poder efectivo y el otro polo sea solamente objeto. (DELFOUR, 2011, p. 27, traducción propia).

El poder de ver al otro a distancia, de ver al otro sin ser visto, puede potencializar las fantasías sádicas, voyeristas y omnipotentes que toman el otro como objeto de gozo, sobre todo una fijación por la satisfacción escópica de la barbarie. El análisis de Delfour (2011) parece un tanto fatalista, pero nos convoca a reflexionar sobre el poder disimulado de las prótesis televisuales y de como estos instrumentos pueden estar a servicio de la democratización de la tiranía.

Freud (2010) señaló que los seres humanos se han especializado en el uso de prótesis tecnológicas para expandir sus habilidades sensoriales, comunicacionales, cognitivas y locomotoras. En la actualidad, los ordenadores e internet son verdaderas extensiones de nuestro cerebro, guardan recuerdos, nos ayudan con los cálculos y amplían demasiadamente nuestra capacidad de comunicación. Por esta razón, necesitamos comprender cada vez más el juego del poder psicológico implicado en estos dispositivos.

En 2004, el presidente de la mayor televisión francesa hizo una afirmación polémica: "nuestro programa tiene por vocación hacerlo disponible [el cerebro], es decir, entretenerlo, relajarlo para prepararlo entre un anuncio y otro. Lo que vendemos a la Coca-cola es el cerebro humano disponible" (JEANNENEY, 2006, p. 31, traducción propia). Esta declaración nos remite al predominio de los principios de Adam Smith, el famoso economista inglés que ha defendido la idea de una mano invisible guiando la economía. De hecho, las manos invisibles que operan en internet, casi siempre, tienen orígenes norteamericanos, organizan las informaciones que circulan en la red, vigilan nuestras huellas digitales, además, crean una profusión de gadgets, softwares e imágenes técnicas que compiten por la atención de las personas de todo el mundo.

El filósofo checo Vilém Flusser, que vivió en Brasil entre 1940 y 1971, fue uno de los primeros pensadores a tratar de la filosofía de la informática. En $O$ 
universo da imagen técnica: o elogio da superficialidade, analizó el poder de la imagen técnica actuando en el ámbito de las virtualidades, con tránsito entre lo probable y lo improbable: "las imágenes técnicas engañan el ojo para que el ojo no perciba a los intervalos" (FLUSSER, 2008 p. 29, traducción propria), estas ocultan el programa, el programador y el sistema.

Los trabajos de Flusser son prácticamente profecías de la inteligencia artificial y de una sociedad digital cada vez más dependiente de un sistema informativo. En su visión: "el comportamiento de los individuos y de la sociedad está siendo programado por diferentes dispositivos [...] y la propia programación humana va siendo programada por los dispositivos" (FLUSSER, 2011, p. 43-4, traducción propia). En otras palabras, los programadores proyectan comportamientos, pero también están programados por una sociedad programática, donde nadie escapa, ni aquellos que creen dominar la máquina. Esa programación actúa directamente en el inconsciente, de manera insidiosa, de forma que el sujeto ni se cuestione de dónde viene la mano invisible que programa sus hábitos y creencias.

Es importante destacar que la neocolonización digital solo es posible porque simultáneamente adoptamos perspectivas pedagógicas que favorecen la perpetuación de la ignorancia y de las desigualdades. Freire (1997) destacó que las teorías importadas y recetas de educación hacían parte de las estrategias de dominación impetrada por una élite. A pesar de que nos haya alertado Freire, aún es importante un examen de cómo el sistema educativo brasileño mantiene profundas contradicciones, quedándose prisionero de algunas ilusiones pedagógicas, las cuales destacaremos adelante.

\section{LA ESCUELA CONTRA ELLA MISMA Y LAS TEORÍAS PEDAGÓGICAS NEOLIBERALES}

Los mecanismos de opresión tienen una capacidad inmensa de autoregeneración, es decir, pueden tomar las críticas y convertirlas en beneficios para sí. En Brasil, durante la dictadura militar, la escuela llegó a ser considerada un medio de adoctrinamiento para formar seres humanos obedientes y pasivos, tal como describió Freire (2005) sobre la pedagogía bancaria. Sin embargo, las críticas generales dirigidas a las escuelas, a los profesores y a sus conocimientos transmitidos, junto con la baja inversión pública en la educación y en la formación de profesores, han contribuido para generar un clima de falta de credibilidad en 
las instituciones educativas con importantes consecuencias para la educación brasileña. Además, con la expansión del acceso a las tecnologías digitales y la profusión de informaciones ni siempre científicas, alumnos pasan a enfrentar a los profesores con teorías muchas veces inconsistentes, provenientes de vídeos de YouTube. Como ejemplo tenemos las comunidades de tierraplanistas, que se expanden en Brasil y han provocado tensiones en clases escolares por sus creencias de que la tierra sea plana. Muchos de ellos creen que los profesores deben aceptar democráticamente sus posicionamientos.

En efecto, se ha ampliado considerablemente el acceso a la escuela en Brasil y se ha abierto camino para una educación más democrática. Aun así, como bien explica el filósofo Marcel Gauche (2002), la democracia, muchas veces, funciona contra sí misma. El filósofo argumenta que la perspectiva más democrática de la sociedad ha estado ancorada en principios que exaltan el individualismo. Para formar un individuo supuestamente libre y autónomo, la escuela también ha hecho permutaciones, basada principalmente en los ideales de la Escuela Nueva ${ }^{3}$. En consecuencia, presupuestos de la educación han cambiado de una perspectiva de mayor vínculo del individuo con las normas colectivas a una autonomía subjetiva apoyada por la promoción del individualismo (GAUCHE, 2002).

Dos puntos contradictorios están en la base de la educación contemporánea: los derechos de libertad y autonomía de los niños de un lado, y de otro, la creciente obsesión por protección, por los excesivos cuidados y exigencias de que los educadores formen individuos con competencias cada vez más complejas. La solución es una autoridad tutelar muy hábil en disimular su tutela:

La utopía por excelencia del gobierno de los hombres en el cuadro de la sociedad de los individuos: les conducir y les constituir plenamente, pero sin jamás les contraer, de tal manera que todo sea vivido por ellos propios, como si tuviesen una iniciativa autónoma. (GAUCHE, 2002, p. 13, traducción propia).

La condición de vulnerabilidad de la etapa infantil exige un poder tutelar, una responsabilidad colectiva con la prerrogativa de inserción del niño en la sociedad. No obstante, el enfoque en la autonomía subjetiva, en su derecho de identidad y

\footnotetext{
${ }^{3}$ Escuela Nueva: movimiento que surgió al final del Siglo XIX, a partir de críticas a la pedagogía tradicional y que asume grandes dimensiones en Brasil, con propuestas de reforma en la educación nacional, sobre todo a partir de la década de 1930.
} 
singularidad, ha oscurecido y enflaquecido el papel de los educadores, al mismo tiempo en que se fortalecen las autoridades mediáticas gobernadas por las manos invisibles del mercado.

Uno de los posibles efectos de este dispositivo en los estudiantes de las clases sociales más abastadas es la formación de una generación dependiente, con poca tolerancia a las frustraciones e impregnada de soberbia. Para los estudiantes de clases populares, los efectos pueden ser más nefastos debido al abandono y precarización de la enseñanza, contribuyendo para formar una generación sin conocimientos históricos y científicos que puedan cambiar la realidad de exclusión, como era la propuesta de Freire. Lo que resulta en una generación con pocos instrumentos para luchar, seducida por pensamientos mágicos y autoritarios.

La creencia de que la democratización interna de las escuelas sería suficiente para la formación de una generación más consciente y capaz de participar críticamente de una sociedad democrática ha sido cuestionada por investigadores brasileños. Saviani (2018) en Escola e Democracia desarrolló un análisis crítico sobre el problema de la marginalidad en América Latina y propuso reflexiones sobre como algunas teorías pedagógicas han influenciado la educación brasileña, a punto de contribuir fuertemente para aumentar las desigualdades.

De acuerdo con Saviani (2018) la concepción tradicional de escuela partía del principio de que el gran obstáculo para la democracia sería la ignorancia del pueblo. La escuela tenía el papel de transmitir conocimientos con el objetivo de disminuir la disimetría entre el pueblo y la burguesía. En contrapunto, la posición de la Escuela Nueva concebía la corrección de las desigualdades por medio de la aceptación de todas las individualidades y opiniones.

Los presupuestos de la Escuela Nueva influenciaron una visón utópica y neoliberal de la educación:

Las consecuencias fueran más negativas que positivas, una vez que, provocando el aflojamiento de la disciplina y la falta de preocupación por la transmisión de los conocimientos, terminó por rebajar el nivel de la enseñanza destinada a las capas populares, las que, muy frecuentemente, tienen en la escuela el único medio de acceso al conocimiento elaborado. En contrapartida, la "Escuela Nueva" ha perfeccionado la calidad de la enseñanza destinada a las élites. (SAVIANI, 2018, p. 9, traducción propia). 
A partir de la década de 1990, otro movimiento teórico llega en Brasil: Ias "pedagogías del aprender a aprender". El análisis de Duarte (2001), acerca de la relación entre las ilusiones de la sociedad de los conocimientos y las pedagogías del aprender a aprender, señala algunos puntos interesantes, que corroboran las reflexiones referentes a las utopías individualistas de la autonomía infantil destacadas por Gauche (2002). Uno de los aspectos evidenciados por Duarte (2001) se refiere a la valorización del aprender solo en detrimento de aprender con el otro.

No discuerdo de la afirmación de que la educación escolar deba desarrollar en el individuo la capacidad y la iniciativa de buscar por sí mismo nuevos conocimientos, la autonomía intelectual, la libertad de pensamiento y de expresión. Lo que estoy buscando aquí es analizar otra cosa: se trata del hecho de que las pedagogías del "aprender a aprender" establecen una jerarquía valorativa en la cual aprender solo se ubica en un plan más elevado que el aprendizaje resultante de la transmisión de conocimientos por alguien. Al contrario de este principio valorativo, entiendo ser posible postular una educación que fomente la autonomía intelectual y moral a través justamente de la transmisión de las formas más elevadas y desarrolladas del conocimiento socialmente existente (DUARTE, 2001, traducción propia).

Saviani (2018) y Duarte (2001) critican las ilusiones pedagógicas que se ponen al servicio de la descalificación de las escuelas y de los profesores, pedagogías que desprecian la transmisión de saberes esenciales a la búsqueda de equidad social. Es importante subrayar que dichas ilusiones se originan en un contexto aparentemente crítico e innovador, pero con impactos devastadores en términos de precarización de las condiciones educativas para los más pobres en Brasil. La desvalorización de la escuela y de los conocimientos científicos históricamente acumulados abre una grieta gigantesca para el dominio tecnológico que aquí llamamos de neocolonización digital y que tal vez nos lleve a la creciente imbecilidad colectiva.

Nos impresiona que, a pesar de que Paulo Freire nos haya alertado sobre los riesgos de las teorías colonizadoras, la élite intelectual brasileña, incluso aquella identificada con concepciones más socialistas, cuando asumió el comando de las políticas públicas, siguió propalando ideas importadas que han contribuido para la exclusión de los pobres, en cambio de buscar resultados efectivos educativos que podrían garantizar algún tipo de equidad social. 


\section{ALGUNAS INVESTIGACIONES SOBRE EL USO DE LAS TIC POR ESTUDIANTES BRASILEÑOS}

Esas reflexiones, mencionadas anteriormente, empezaron a ser desarrolladas hace más de diez años, a partir de investigaciones empíricas que he realizado con adolescentes y niños para identificar la influencia de las TIC en sus vidas. Lo que he constatado en las escuelas públicas y privadas confirman las predicciones de Flusser (2008, 2011), Gruzinsk (1990) y Delfour (2011) sobre el poder de dominación por medio de las imágenes técnicas. Confirman también las críticas de Saviani (2018) y Duarte (2011) sobre las teorías pedagógicas que contribuyen para aumentar las desigualdades entre las escuelas para los ricos y para los pobres brasileños, facilitando las neocolonizaciones.

En una investigación con grupos de adolescentes de una escuela pública y otra privada de la ciudad de São Paulo sobre la relación con internet, he identificado que las empresas de videojuegos, redes sociales y entretenimiento digital han pasado a programar prematuramente sus hábitos, especialmente en las comunidades más vulnerables en los aspectos económicos y educacionales. Esos hábitos interfieren en sus gustos, preferencias alimentares, en sus prendas de vestir, en sus videojuegos, lenguajes y en la disponibilidad para el estudio (PRIOSTE, 2016).

Esta investigación también identificó una significativa diferencia entre la manera que los adolescentes de la escuela privada usan los dispositivos tecnológicos en comparación con los estudiantes de la escuela pública. La primera diferencia es que todos los estudiantes de la escuela privada estaban debidamente alfabetizados al final de la enseñanza fundamental ${ }^{4}$ y podían hacer un uso más activo y educativo de la internet. En la escuela pública había algunos jóvenes completamente analfabetos finalizando la etapa fundamental y una mayoría con una alfabetización muy precaria que dificultaba demasiado el uso del ordenador con objetivos educativos (PRIOSTE, 2016).

¿Cómo puede la escuela pública permitir que algunos estudiantes concluyan la educación básica analfabetos? ¿Qué pensaría Freire si viviese hoy? Planteamos esos cuestionamientos porque el pensador brasileño ha dedicado gran parte de sus reflexiones en el tema de la alfabetización y en este punto no tuvimos grandes

\footnotetext{
${ }^{4}$ En Brasil la educación fundamental corresponde en general a la edad entre 6 y 14 años.
} 
avances.

La segunda diferencia evidenciada entre los estudiantes de la escuela privada y pública es que, en la primera, los estudiantes no avanzaban las etapas sin dominio mínimo de contenidos y de competencias básicas, que eran evaluadas periódicamente. Aquellos que tenían dificultades recibían soporte de la escuela o de profesionales especializados, y repetían la etapa cuando el equipo pedagógico juzgaba más adecuado. En la escuela pública predominaba una política en que todos avanzaban las etapas, aunque no tuviesen el dominio de competencias básicas, y prácticamente no había soporte para los que enfrentaban dificultades de aprendizaje. Se trata claramente de una política cuyo objetivo era la reducción de costos, pero con fachada pedagógica, y poco importaba lo que sería mejor para el estudiante (PRIOSTE, 2016).

Una élite intelectual, aparentemente solidaria con los pobres, aún defiende vehementemente el discurso de no repitencia, a pesar de que la mayoría de sus hijos estudien en escuelas privadas con reglas bastante estrictas sobre reprobación. No se trata aquí de defender las políticas de repitencia punitiva y sin apoyo, sino de explicitar que las soluciones importadas, sin la debida evaluación de los resultados, pueden aumentar la distancia entre quien domina los códigos de la cultura y aquellos que serán tratados como objetos y seres descartables. Freire (1997) ya denunciaba el asistencialismo y paternalismo como forma de dominación y sumisión. Actualmente, las clases con grupos abarrotados y muy heterogéneos de las escuelas públicas son una forma de inviabilizar la posibilidad de una educación reflexiva y liberadora.

La tercera diferencia está relacionada con la capacidad de gestión de los conflictos. La escuela privada tenía profesionales disponibles para ayudar a los profesores y alumnos, así como reglas de conducta más claras, con consecuencias efectivas. En la escuela pública, el profesor de informática observado gastaba una gran parte del tiempo de clase administrando los conflictos e incluso las conductas violentas del grupo, o sea, quedaba muy poco tiempo dedicado para la enseñanza. Era perceptible la falta de respeto de los alumnos hacia el profesor, dirigiéndole bromas ofensivas a las que él soportaba cotidianamente. Además, muchos estudiantes entraban en las clases con sus dispositivos móviles, headphones y se recusaban a guardarlos (PRIOSTE, 2016). Ese clima permisivo y chocante parece tener fuerte relación con la caída de la reputación del profesor y de la escuela. 
O sea, la aparente democracia de la escuela tiene un efecto antidemocrático como nos alertó Saviani (2018), a medida que priva a los estudiantes de saberes fundamentales para la vida comunitaria.

Por último, conviene subrayar la diferencia de estructura tecnológica de la escuela pública y de la privada. En la pública había un número reducido de ordenador por alumno y menos de cincuenta minutos de actividades de informática educativa por semana. El profesor era el único responsable por la instalación de los equipamientos y una parte de ellos siempre presentaba problemas. Los filtros de protección no funcionaban adecuadamente y los adolescentes lograban acceder a juegos violentos e imágenes pornográficas durante las clases. En cambio, en la escuela privada había un mayor número de ordenadores por alumnos y, casi siempre, los jóvenes tenían una supervisión tecnológica individualizada para los proyectos pedagógicos desarrollados en las clases, además de un equipo de soporte técnico que garantizaba el funcionamiento de las máquinas y la efectividad de los filtros de protección (PRIOSTE, 2016).

Esa investigación ha revelado que los adolescentes que viven en los suburbios de São Paulo, mismo en condiciones económicas precarias, no dejan de adquirir smartphones, gorros, camisas o pares de zapatillas de marcas estadounidenses, productos siempre muy costosos en Brasil, pero que para ellos simbolizan pasaportes de pertenencia social. Muchos jóvenes son bastante fragilizados desde un punto de vista psicológico, educativo y cultural, y aún contribuyen a enriquecer a las compañías extranjeras. Algunos se sentían engañados por una escuela supuestamente democrática que les privaba de conocimientos básicos para vivir en el mundo competitivo de la sociedad de la información. Jóvenes con poca consciencia de sus raíces culturales y que se descubren con baja perspectiva estudiantil (PRIOSTE, 2016). Freire ya denunciaba, en los años de 1970, la idealización del brasileño hacia los productos extranjeros, como también las manipulaciones publicitarias. En la era digital esos aspectos parecen ser más contundentes y las observaciones de Freire son muy actuales.

Con base en los resultados de esta investigación con los jóvenes, pasé a cuestionar si los hábitos televisuales de los niños más pobres podrían afectar el proceso de alfabetización, así, en 2015 empecé investigaciones con estudiantes entre 8 y 10 años, exclusivamente de escuelas públicas en barrios periféricos. A partir de esos estudios, pude identificar que el exceso de televisión, videojuego, 
tablet y smartphone tiene disminuido el interés de los niños por actividades escolares (PRIOSTE, 2017), confirmando las investigaciones de Desmurget (2012) sobre como las pantallas afectan la capacidad del esfuerzo intelectual. En cambio, las investigaciones confirmaron que la alfabetización era un factor importante para la protección del niño en los ambientes digitales, como también era fundamental la mediación de los padres.

Así como en la colonización tradicional los investigadores identificaron resistencia y sincretismo, no se puede decir que los jóvenes estén totalmente pasivos ante ese proceso digital, esa consciencia depende mucho de la educación que reciben en la familia, en la comunidad y en la escuela. Nuestras investigaciones y reflexiones apuntan apenas tendencias. Conviene subrayar que en Brasil hay una gran diversidad de escuelas públicas y privadas y es importante un cuidado con generalizaciones. Además, la juventud brasileña es también muy heterogénea y quizá la internet pueda favorecer colectivos y movimientos multiculturales de resistencia y de conciencia política contra el neocolonialismo digital.

\section{6 ¿EN LA ERA DIGITAL, AÚN SERÍA POSIBLE UNA PEDAGOGÍA LIBERADORA COMO PAULO FREIRE HA IDEALIZADO?}

Al proponer una pedagogía liberadora, necesitamos en primer lugar cuestionar: ¿liberación de quién y para qué? No podemos pensar en una pedagogía liberadora sin la comprensión de los nuevos mecanismos de esclavitud psicológica televisiva y digital, que a menudo estimulan los impulsos arcaicos y narcisistas del individuo. Tampoco podemos pensar en una educación liberadora sin levar en cuenta los cambios de las escuelas y los discursos pedagógicos que sustentan las desigualdades. Como ha destacado Dufour (2007) sobre los discursos neoliberales:

iLiberénme de todo lo que me aliena (las instituciones, la cultura, la civilización, la lengua, los significantes, el nombre del padre, los saberes, los poderes, etc.) y podrán ver lo que pasa! Y vimos: los filósofos posmodernos no se dieron cuenta de que la liberación del sujeto, antes confinado en la prisión institucional, sólo podía contribuir para un aprisionamiento más terrible aún, a saber, la prisión del pequeño ego sometido a sus propias pulsiones (DUFOUR, 2007, p. 187, traducción propia).

Por lo tanto, una pedagogía liberadora debe comprender que las pulsiones sádicas no son privilegios de los opresores, están presentes también en los 
oprimidos. Los profesores, las escuelas, las reglas sociales y los conocimientos tradicionales se transforman en enemigos del individuo libre. Sin embargo, ¿̇será qué esos son los verdaderos enemigos?

En el contexto actual de la neocolonización digital en Brasil, hay en las redes sociales movimientos que incentivan a que los alumnos denuncien sus profesores por medio de vídeos, en el caso de que consideren la enseñanza como adoctrinamiento político. Los profesores no sólo son cuestionados, sino cerceados en su libertad de cátedra, así como, muchas veces, pasan a ser humillados y víctimas de violencias desmedidas. Las satisfacciones sádicas y exhibicionistas contra los profesores son el resultado de la omnipotencia de los oprimidos que no saben de qué manera, ni contra quién luchar, y acaban por identificarse con los opresores. Los espacios digitales son transformados en escenarios de ofensas, con una platea voraz y vengativa.

Freud (2010) ha revelado que los mayores obstáculos para la civilización son los impulsos destructivos de los individuos, sus tendencias agresivas, narcisistas y de dominación. De esa manera, una educación verdaderamente liberadora no puede ser ingenua, debe considerar la complejidad de los seres humanos, incluso sus aspectos inconscientes y autodestructivos, que han sido ampliamente explorados por la industria del entretenimiento digital.

El sueño del oprimido en transformarse en opresor, como nos advirtió Freire (2005) es ampliamente estimulado en juegos, en películas violentas, en diseños animados, series estadounidenses y redes sociales. Un ejemplo es el videojuego Grand Theft Auto (GTA), prohibido para los menores de 18 años, y que ha sido el más jugado por niños en las comunas de São Paulo. Las misiones de robar autos, vender drogas, violar mujeres y matar personas con refinamientos de crueldad son atrayentes a los niños. Lo más grave: los estudiantes lo jugaban en ordenadores de la escuela pública, lo que evidencia la permisividad de los educadores y de las familias, como también la dificultad de percepción de los efectos nocivos de ese tipo de producción (PRIOSTE; MAZZEU; GILIOTTI, 2018).

Hannah Arendt (1972) en "La crise de l'éducation" subrayó la peligrosa creencia de que los niños puedan autogobernarse, como si no fueran necesarios los adultos en el proceso. Para la filósofa, "el niño debe ser especialmente protegido y cuidado para evitar que el mundo pueda destruirlo. Pero este mundo también tiene necesidad de una protección que lo impida ser devastado por las nuevas 
generaciones" (ARENDT, 1972, p. 238-239, traducción propia). De ese modo, una pedagogía liberadora debe ofrecer protección a los niños en los distintos ambientes, incluso en los espacios digitales, pero debe aún protegerlos de sus propias pulsiones tiránicas y destructivas.

Los estudios basados en la perspectiva del psicoanálisis nos muestran la importancia de que las pulsiones agresivas, presentes desde la más precoz infancia, como nos ha revelado Freud (1996), deberían pasar por un proceso de sublimación por medio de las actividades intelectuales y artísticas, diferentemente de lo que ha ocurrido en internet y en los juegos digitales, donde son híper estimuladas. En consecuencia, es fundamental una sólida formación cultural del profesor, como ha propuesto Arendt (1972) para que se pueda despertar en los estudiantes ganas por el saber y por la cultura, ayudando en el proceso sublimatorio.

Freire (1997) también creía en la importancia de una educación con enfoque en el desarrollo intelectual y en la apropiación de nuestras raíces históricas, con vistas a la comprensión de los mecanismos de opresión. El primer paso para ese desarrollo aún es, sin duda, la alfabetización, pero no se debe agotar en ella. Desafortunadamente, en este aspecto, Brasil sigue con graves problemas. Nos preguntamos sobre la influencia de las concepciones pedagógicas mencionadas por Saviani (2018) y Duarte (2001) en el proceso de alfabetización, como también sobre la influencia de las manipulaciones de los hábitos televisuales de los niños, debilitando la capacidad de esfuerzo intelectual y estimulando pulsiones sádicas y omnipotentes.

Por otro lado, aún podemos constatar un pequeño movimiento de resistencia a la neocolonización digital y una búsqueda de valorización de la escuela por parte de los jóvenes. Un ejemplo fue el movimiento de ocupaciones de las escuelas por los estudiantes secundaristas de la ciudad de São Paulo en 2015 y 2016 con el reto de impedir el cierre de sus aulas y de luchar por mejores condiciones estructurales para la enseñanza. El grito de guerra del movimiento fue: "el profesor es mi amigo, si te metes con él, te metes conmigo". En 2019, los estudiantes universitarios, juntamente con los secundaristas han vuelto a ocupar las calles contra los cortes de financiamiento en las universidades y han incorporado el mismo grito. Dichas manifestaciones pueden tener influencia de las interacciones en las redes sociales, sobre todo porque muchos jóvenes tienen sus profesores como contactos en su red de amigos. 
Así, es cada vez más importante que los profesores ocupen también los espacios digitales y puedan promover reflexiones críticas y culturales en sus interacciones. Internet tiene un potencial pedagógico que necesita ser explorado por los docentes, por lo tanto, la escuela no debe limitarse a sus paredes, en realidad, debe aprender a hablar el lenguaje digital de los jóvenes si desea ayudar a libertarlos de la opresión invisible. Por otra parte, la escuela debe tener el coraje de cuestionar antiguas teorías que fortalecen sistemas educativos desiguales.

\section{CONSIDERACIONES FINALES}

En Brasil, hemos visto que el culto de la autonomía y del individualismo, probablemente con influencia de una interpretación limitada de las ideas de Paulo Freire, ha provocado una anomia, cuyas leyes y normas colectivas terminan por suplantarse por el culto hedonista, incluso tiránico. Efectivamente, con la ausencia de un proceso de formación humanística y crítica, sin un sentido de colectividad, el espacio escolar se vuelve vulnerable a todo el tipo de incivilidad, que se perpetúa en los medios digitales.

Puesto que las críticas de Freire, sobre la pedagogía bancaria y autoritaria en la época de la dictadura, puedan haber servido de estuche para que la élite brasileña precarice la enseñanza de las capas populares, la importancia del pensamiento de Freire sobre la formación sólida de ciudadanos conscientes de su Historia y de los procesos opresivos son cada vez más relevantes. En la era digital es esencial formar sujetos críticos que sepan leer lo que está por detrás de la imagen técnica y esto sólo es posible con una metodología dialógica, cuya realidad puede ser problematizada colectivamente. Sin embargo, esta formación crítica depende esencialmente de la transmisión de conocimientos de manera estructurada como defiende Saviani (2018), Duarte (2001) y Dufour $(2007,2009)$. No se puede confundir una perspectiva dialógica con el abandono de la enseñanza pautado en una supuesta autorregulación de los niños.

La autonomía del sujeto debe nacer de la heteronomía, de los lazos constructivos de unos con otros, y con las normas que garantizan el bienestar colectivo. Si queremos preparar a los niños para protagonizar el futuro, es esencial capacitarlos para la decodificación de las imágenes técnicas. Según Flusser: "descifrar imágenes técnicas implica revelar el programa desde el cual y contra el 
cual han surgido. Descifrar las imágenes tradicionales implica revelar la visión del productor, su 'ideología'” (FLUSSER, 2008, p. 29). Así, necesitamos enseñar a los niños a descifrar las ideologías colonizadoras del pasado, que nos impusieron un pensamiento religioso fatalista, como también descifrar las seductoras imágenes técnicas, por las cuales nuestras fantasías y anhelos son manipulados en dirección al consumismo y a la omnipotencia simplista.

Flusser $(2008,2011)$ y Freire (2005) destacaron la importancia del diálogo y de la decodificación de las relaciones de poder como un medio de promover la conciencia crítica. Para enfrentar a la neocolonización digital, la escuela debe en primer lugar garantizar la alfabetización, cuestionando modismos pedagógicos productores de alumnos y de profesores fracasados. En segundo lugar, la escuela debe protagonizar la enseñanza sobre nuestras raíces históricas de opresión y promover una educación crítica para los medios de comunicación, incluyendo propuestas para las familias. De la misma manera que Freire (2005) problematizaba situaciones límites de la realidad de los campesinos, el educador contemporáneo puede problematizar contenidos mediáticos, juegos digitales, publicidades, programas de televisión, películas y redes sociales.

Otro factor importante es la enseñanza de las TIC en las escuelas para que los niños se conviertan en activos y no meros esclavos de la industria del entretenimiento. El mito de que los niños desarrollan sus propias capacidades tecnológicas debe ser cuestionado. Para que actúen como protagonistas, necesitan cada vez más dominar las reglas del mundo digital, y para ello, la mediación por los profesores se hace esencial.

Finalmente, es fundamental crear sueños colectivos que inspiren a los niños y a los jóvenes a superar las adversidades y las desigualdades sociales en la búsqueda de un mundo sostenible, justo y de paz. Una educación para el protagonismo tecnológico sólo es posible con una consistente base humanística y cultural.

\section{REFERENCIAS}

ARENDT, Hannah. La crise de l'education. In ARENDT, Hannah. La crise de la culture. Paris: Gallimard, 1972.

BOSI, Alfredo. Dialética da colonização. São Paulo: Companhia das Letras, 1992. 
DESMURGET, Michel. TV lobotomie: la verité scientifique surles effets de la télévision. Paris: Max Milo Éditions, 2012.

DELFOUR, Jean-Jacques. Télé, bagnole et autres prothèses du sujet moderne: essai sur la jouissance technologique. Paris: Éditions Érès, 2011.

DUARTE, Newton. As pedagogias do "aprender a aprender" e algumas ilusões da assim chamada sociedade do conhecimento. Revista Brasileira de Educação, n.18, p.35-40, set/dez. 2001. Disponível em: <http://www.scielo.br/pdf/rbedu/n18/n18a04>. Acesso em: 25 mai.2019

DUFOUR, Dany-Robert. Le divin marché: la révolution culturelle libérale. Paris: Denoël, 2007.

DUFOUR, Dany-Robert. La cité perverse: libéralisme et pornographie. Paris: Denoël, 2009.

FLUSSER, Vilém. Pós-História: vinte instantâneos e um modo de usar. São Paulo: Annablume, 2011.

FLUSSER, Vilém. O universo das imagens técnicas: elogio da superficialidade. São Paulo: Annablume, 2008.

FREIRE, Paulo. Pedagogia do oprimido. São Paulo: Paz e Terra, 2005.

FREIRE, Paulo. La educación como práctica de la libertad. Madrid: Siglo Veintiuno Editores, 1997.

FREUD, Sigmund. O mal-estar da civilização. In: FREUD, S. Obras completas. Tradução de Paulo César de Souza. São Paulo: Companhia das Letras, 2010. v. 18. (Obra original publicada em 1930).

FREUD, Sigmund. Três ensaios sobre a teoria da sexualidade. In Edição standard brasileira das obras completas de Sigmund Freud. Tradução de Jayme Salomão. v.7. Rio de Janeiro: Imago, 1996. (Obra original publicada em 1905)

GALEANO, Eduardo. Las venas abiertas de America Latina. Buenos Aires: Siglo XXI, 2010. (Obra original publicada en 1970).

GAUCHE, Marcel. La démocratie contre elle-meme. Paris: Gallimard, 2002.

GRUZINSK, Serge. La guerre des images: de Christophe Colomb à 'Blade Runner' (14922019). Paris: Fayard, 1990. 
JEANNENEY, Jean-Noël. Quando o Google desafia a Europa: em defesa de uma reação. Rio de Janeiro: Contracapa, 2006.

PRIOSTE , Cláudia. O adolescente e a internet: laços e embaraços no mundo virtual. São Paulo: Edusp, 2016.

PRIOSTE, Cláudia. O Homo zappiens e o uso dos dispositivos televisuais: possíveis impactos no processo de alfabetização. Conhecimento \& Diversidade, Niterói, RJ, v. 9, n. 18, p. 73-88, jul./set. 2017.

PRIOSTE, Cláudia; MAZZEU, Francisco José Carvalho; GILIOTTI, Letícia. Riscos online e jogos violentos: análise das atividades infantis na internet. Revista Tecnologia Educacional, Rio de Janeiro, n. 221, p. 113-23, abr./jun. 2018.

SAVIANI, Dermeval. Escola e democracia. Campinas, SP: Autores Associados, 2018.

\section{Sobra a autora:}

Cláudia Dias Prioste: Professora Assistente Doutora no Departamento de Psicologia da Educação. Formação em Psicologia e Doutorado em Educação pela Universidade de São Paulo com estágio na Univesidade Paris 8. Coordenadora do grupo de pesquisa "A formação do sujeito na era digital". Está credenciada nos programas de Pós-Graduação em "Educação Escolar" e em "Educação Sexual". E-mail: claudiaprioste@gmail.com, Orcid: http://orcid.org/0000-0001-6824-3410

\section{Recebido em março de 2019 Aprovado em agosto de 2019}


